\title{
Use of time in people with chronic obstructive pulmonary disease - a systematic review
}

\author{
This article was published in the following Dove Press journal: \\ International Journal of COPD \\ 12 December 2014 \\ Number of times this article has been viewed
}

\author{
Toby Hunt ${ }^{1,2}$ \\ Sarah Madigan ${ }^{2}$ \\ Marie T Williams ${ }^{3}$ \\ Tim S Olds'
}

'Alliance for Research in Exercise, Nutrition and Activity (ARENA), Sansom Institute for Health Research, School of Health Sciences, University of South Australia, City East Campus, Adelaide, SA, Australia; ${ }^{2}$ Respiratory Clinical Research Unit, Repatriation General Hospital, Daw Park, SA, Australia; ${ }^{3}$ School of Population Health, University of South Australia, City East Campus, Adelaide, SA, Australia

Correspondence: Toby Hunt Respiratory Clinical Research Unit, Repatriation General Hospital, Daw Park, SA, 504I, Australia Tel +6I 882751023 Fax +6I 88275 II95

Email toby.hunt@health.sa.gov.au

\begin{abstract}
Physical inactivity" and "sedentary lifestyles" are phrases often used when describing lifestyles of people with chronic obstructive pulmonary disease (COPD). Evidence suggests activity types, independent of energy expenditure, influence health outcomes, so understanding patterns of time use is important, particularly in chronic disease. We aimed to identify reports of time use in people with COPD. Predefined search strategies were used with six electronic databases to identify individual activity reports (including frequencies and/or durations) in which community-dwelling people with COPD engaged. Eligible studies were assessed independently against predefined criteria and data were extracted by two reviewers. Data synthesis was achieved by aggregating activity reports into activity domains (sports/exercise, screen time, transport, quiet time, self-care, sociocultural, work/study, chores, and sleep). Twenty-six publications reported 37 specific daily activities. People with COPD were found to spend extended periods in sedentary behaviors (eg, standing [194 min/day]; sitting [359 min/day]; lying [88 min/day]), have limited engagement in physical activity (eg, walking [51 min/day]; exercising [1.2 episodes per week $\{\mathrm{ep} / \mathrm{w}\}, 13 \mathrm{~min} /$ day] $)$, have high health care needs (medical appointments [1.0 ep/w]), and experience difficulties associated with activities of daily living (eg, showering $[2.5 \mathrm{ep} / \mathrm{w}$, 60 minutes per episode]; preparing meals [4.7 ep/w]). Little data could be found describing how people with COPD use their time, and data synthesis was problematic because of variations in methodologies, population differences, and research emphases. Identified data largely referred to posture and were skewed according to country, assessment methods, and disease severity. Comparisons with age-matched population data showed people with COPD spent less time engaged in personal-care activities (self-care and sleeping) and chores than people in similar age groups. The incorporation of time-use outcomes in future research designs should be encouraged. Ideally, these tools should use consistent frameworks and comparable outcome measures in order to provide clearer descriptions of time use in chronic disease.
\end{abstract}

Keywords: activities of daily living, human activities, leisure activities, sedentary lifestyles

\section{Introduction}

The ways in which people spend their days are diverse and complex. In youth and adult populations, exploring how people spend their days is often achieved through use of time profiles. The term "use of time" refers to how an individual spends their time; specifically, which activities they engage in and when. Activities sharing similar characteristics (eg, activities requiring low levels of energy expenditure, such as reading, watching television, or sitting) can be aggregated into domains (eg, "sedentary behavior"). Activity choices are impacted by conscious and unconscious decisions, pressures from the social and built environments, symptom perception, personal autonomy, social interaction, desirability, and necessity. ${ }^{1}$ Significant differences are therefore likely in populations with distinct characteristics (eg, age, sex, health status). 
In the last decade, many researchers have assessed sedentary and physical behaviors in people with chronic obstructive pulmonary disease (COPD), leading to a number of self-report (questionnaires and/or diaries) and objective (motion sensors and/or activity monitors) collection methods. $^{2}$ The use of these tools in COPD populations has led to the consensus that people with COPD have reduced daily activity levels and increased periods of sedentary behaviors. ${ }^{3-7}$ While these studies report a global picture (eg, daily moderate to vigorous physical activity [MVPA] or sedentary behaviors), they commonly do not describe the specific activities included within these categories. Most often, self-report data-collection methods invite participants to respond to broad statements (eg, to recall or record the time spent in a specific activity or posture over a set period of time), while activity monitors provide descriptive data (ie, frequency, intensity, and/or time of activity).

Knowing about specific activities is important, because particular activity types are linked to specific health outcomes. For example, playing musical instruments and learning languages have been linked to the prevention of cognitive decline, ${ }^{8,9}$ and social interaction has been linked to lower levels of depression ${ }^{10}$ and cardiovascular disease ${ }^{11}$ - all of these are frequent comorbidities with COPD. Understanding how people with COPD use their time would provide opportunities to identify areas/activities which could be added, reduced, or supplemented as a starting point for reducing time spent in sedentary activities and/or increasing time spent in physical activities.

The aim of this systematic review was therefore to identify specific activities (type, duration, and/or frequency) that community-dwelling people with COPD engage in.

\section{Methods}

\section{Protocol and registration}

The protocol was developed using the Preferred reporting items for systematic reviews and meta-analyses (PRISMA) guidelines, ${ }^{12}$ and was registered on Prospero, the international prospective register of systematic reviews (protocol registration number CRD42013003747).

\section{Eligibility criteria}

All original research articles published in peer reviewed journals reporting at least one free-living activity engaged in by people with COPD (activity type, duration and/or frequency) were eligible for inclusion (eg, 60 minutes a day walking the dog or brushing ones teeth three times a day). Articles were excluded if the activity was reported as part of an intervention study, assessments were laboratory-based, or participants lived in residential care facilities. Studies reporting activity levels (eg, minutes per day [min/d] of MVPA) were excluded unless a specific activity (eg, walking the dog) was also reported. Likewise, reports of steps per day were excluded unless walking bout length or accumulation patterns were included.

\section{Information sources}

With the aid of an academic librarian, two search strings were developed. The first (use of time) included as many free-living activities as possible. In addition to the phrase "use of time", it included terms associated with specific activity groups (physical activity, screen time, transport, activities of daily living, pastimes, work/study, chores, sleep, and sedentary behaviors). Relevant MeSH headings and individual key words and/or phrases were used to search all available search fields. Each activity group was searched separately and later combined using the Boolean term "OR". The second search string (chronic obstructive pulmonary disease) included the relevant $\mathrm{MeSH}$ headings used to describe COPD. The use of time search string was limited to people with COPD by combining both search strings with the Boolean word "AND". The databases Medline (1946 to present), Embase (1947 to present), EBSCO Host (Academic search premier, Age Line, CINAHL, Health Source, SPORTDiscus; 1961 to present), Science Direct (1823 to present), SAGE Journals Online (1847 to present), and Scopus (1960 to present) were searched. An initial search was conducted in April 2012 with an updated search conducted in June 2013. Complete search strategies for all databases are included in the Supplementary Materials (Table S1.1-S1.6).

Full citation lists from each database were exported to the referencing program EndNote (version X6; Thompson Reuters) where duplicate citations were removed before assessing eligibility in two stages. Each citation was initially assessed against the inclusion criteria using title and abstracts. Where the citation could not be excluded, full texts were accessed and assessed for eligibility. In both stages, two reviewers (TH and $\mathrm{SM}$ ) worked independently, to compare results, and resolve discrepancies by discussion. In the event that consensus could not be obtained or ambiguity existed, full text versions of the articles were provided to a third reviewer for comment (MTW).

\section{Data collection}

Primary outcome data were extracted from each included paper using a prospectively designed data extraction tool. 
Publication details (title, contact author, journal name, and country of research), study population (number of COPD participants, demographics, severity of respiratory impairment), and activity outcomes (activity type, duration, and frequency) were extracted verbatim.

A random sample of the eligible articles (15\%) was used to test for extraction consistency. No refinements were required. Two independent assessors (TH and SM) then extracted relevant data from the retained articles.

\section{Assessment of study quality and publication bias}

Two reviewers (TH and TSO) independently appraised methodological bias using the qualitative ${ }^{13,14}$ and quantitative ${ }^{15,16}$ appraisal tools developed by McMaster University Occupational Therapy Evidence-Based Practice Research Group. Initially developed in 1998 for use in guiding evidence based decision making in occupational therapy, these generic critical appraisal tools were chosen to appraise bias because of their widespread use with varied study designs. Each equally weights eight items in order to rate how well authors have considered issues relating to study purpose, background literature, study design, sampling approach, and conclusions. In addition, three items specific to the research design (qualitative studies: data collection, data analysis, and rigor - quantitative studies: outcomes, interventions, and results) are used.

This review was essentially exploratory; that is, it was designed to incorporate all reports of activities engaged in by people with COPD, regardless of their study design or their findings. While studies were assessed for methodological bias and this was reported, excluding studies based on methodological bias was not prospectively planned.

Publication bias was not assessed because the concern that non-published findings may negatively influence this reviews findings was considered minimal.

\section{Synthesis and analysis of results}

This review was summarized using a narrative approach. Use-of-time tools (eg, recall questionnaires or time-use diaries) record the "what" and "when" of daily routines, grouping together activities that share similar characteristics. The hierarchy with which activities are grouped differs among use-of-time tools. We elected to synthesize our data using the activity domains used by the Multimedia activity recall for children and adults (MARCA). The MARCA is a computer-based instrument that uses a structured interview format to record and construct detailed daily activity profiles.
It records each activity undertaken between "anchor points" (midnight, breakfast, lunch, and dinner) in time slices as small as 5 minutes. The MARCA was chosen to synthesize data for the present review because it has an extensive activity library ( $>500$ distinct activities) which, via an energy-expenditure compendium, links individual activities to estimated energyexpenditure values. The MARCA also has a growing bank of disease-specific time-use data and shows high reliability (test-retest correlations consistently $>0.9$ ) and moderate to strong $\left(r_{s}=0.43-0.80\right)$ validity correlations in people with COPD. ${ }^{17}$

Individual activities included in the MARCA's activity database are grouped into one of nine broad activity domains (sports/exercise, screen time, transport, quiet time, self-care, sociocultural, work/study, chores, and sleep) (see Table S2). Together these activity domains cover the majority of commonly reported activities. ${ }^{18}$ When allocating activities to domains, careful consideration was given both activity types and supporting contextual information (eg, the "with whom, where, and why" of each activity). Where such information was lacking, activities were allocated to domains with the broadest applicability (eg, sitting was placed into quiet time).

To synthesize data, duration-based reports in $\mathrm{min} / \mathrm{d}$ and frequency-based reports in episodes per week (ep/w) were calculated. If outcome data was not presented in this format, data conversions were undertaken (eg, conversion of hrs/d to $\mathrm{min} / \mathrm{d}$ by multiplying by 60 [eg, 5 hours of nightly sleep ${ }^{19}=$ $300 \mathrm{~min} / \mathrm{d}$ ], and converting the number of reports for a given activity divided by the number of participants and the data collection period [eg, 165 episodes of stair climbing reported by 17 participants over a 14 day period $\left.{ }^{20}=4.8 \mathrm{ep} / \mathrm{w}\right]$ ). Where possible, ranges and medians for individual activities were reported.

\section{Results}

The initial database searches in 2012 provided a total of 43,671 citations, with the 2013 update providing an additional 4,644 citations. After removing duplicate citations $(n=10,618), 37,697$ abstracts were reviewed for eligibility with 37,126 excluded and 571 full text articles reviewed (Figure 1; Tables S3.1-S3.7). Twenty-seven of these articles were deemed eligible for inclusion in this review. One study was excluded from the review (after unsuccessful attempts to contact the authors) as data for a variety of individual activities were presented in graphical format without numerical data. ${ }^{21}$ Table 1 presents the characteristics of each included study. 


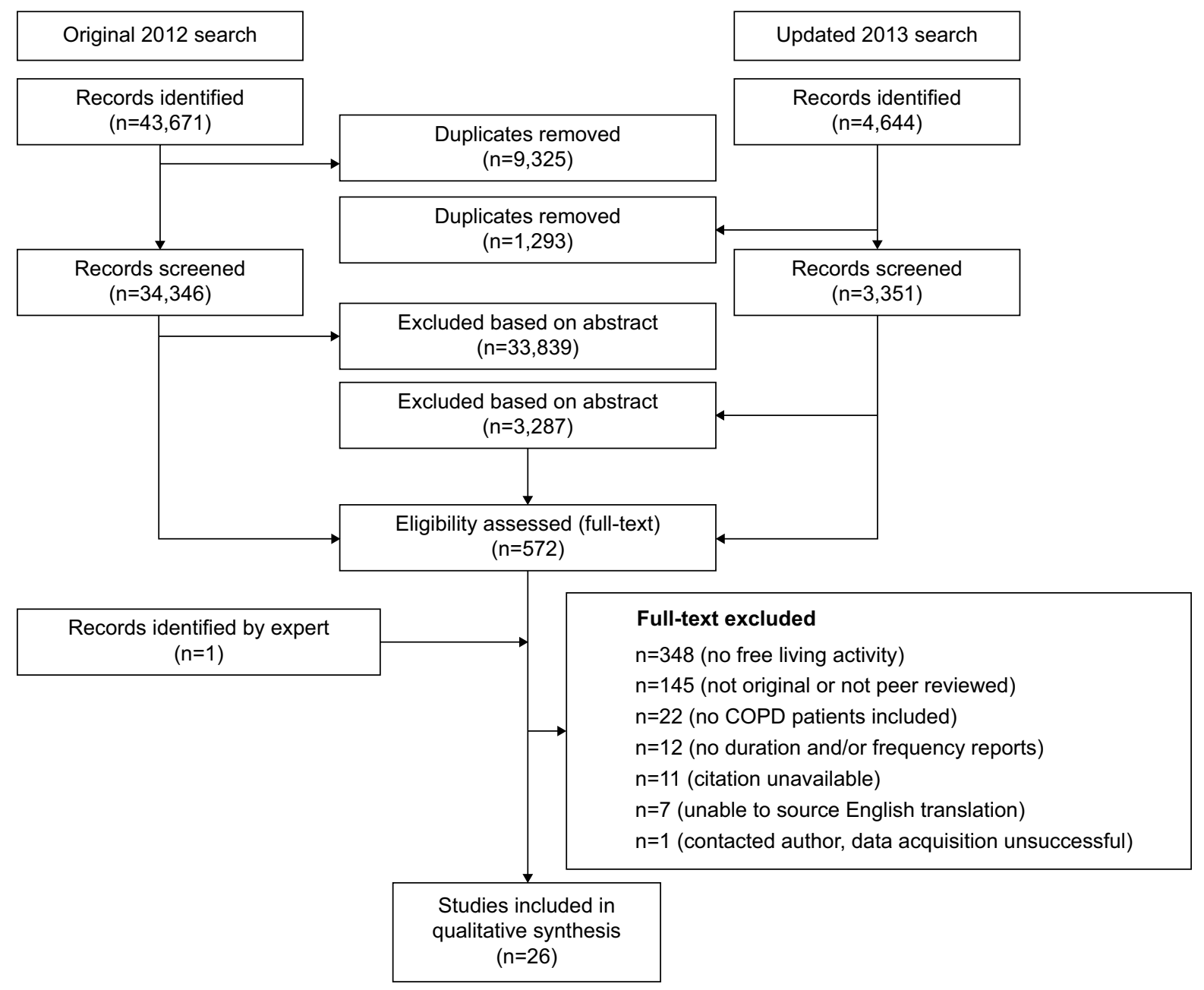

Figure I Consort diagram showing search process and identification of eligible studies for this review. Abbreviation: COPD, chronic obstructive pulmonary disease.

Significant heterogeneity existed within many aspects of the studies. Quantitative research, accounting for $80 \%(\mathrm{n}=21)$ of the studies, included five different activity monitors (Dynaport, ${ }^{22-32}$ Airpermon, ${ }^{33,34}$ Actiped, ${ }^{20}$ Motionlogger, ${ }^{35}$ and Sensewear $\left.{ }^{5,25,26,32}\right)$ and four broad types of activity questionnaires (work productivity, ${ }^{36}$ activity recall, ${ }^{5,20,37,38}$ erectile function, ${ }^{39}$ and epidemiological ${ }^{40}$ ). Three studies incorporated multiple activity monitors in their study design, ${ }^{25,26,32}$ while three others included both activity monitors and questionnaires. ${ }^{5,20,30}$ The remaining studies $(\mathrm{n}=5)$ were undertaken using qualitative study frameworks. ${ }^{19,41-44}$

All identified studies were published within the last decade ( $\mathrm{n}=26)$ and over two-thirds $(\mathrm{n}=19)$ originated from Europe. Respiratory impairment, where reported $(n=20)$, ranged from severe (forced expiratory volume in 1 second $\left[\mathrm{FEV}_{1}\right] 25 \%$ predicted) to mild ( $\mathrm{FEV}_{1} 79 \%$ predicted), mean age ranged from 56 to 73 years, and the majority of studies included predominantly male participants $(\mathrm{n}=19)$. In line with differing methodologies, sample sizes varied significantly from small $(n=10)$ to extremely large $(n=5,314)$.

Appraisal of methodological bias showed all studies were undertaken and reported to a high standard (quantitative mean 6.6/8, qualitative mean 6.6/8). Common omissions leading to increased bias included failures to justify sample sizes and/or report clinical implications (qualitative studies), as well as poor study design and/or data collection explanations and sampling methodology omissions (quantitative studies). Appraisal of bias summaries can be found in the Supplementary Material (Table S4).

\section{Result synthesis}

Data synthesis was achieved by combining similar activities into predefined activity domains (Table 2). Individual study outcomes can be found in the Supplementary materials (Table S5). 


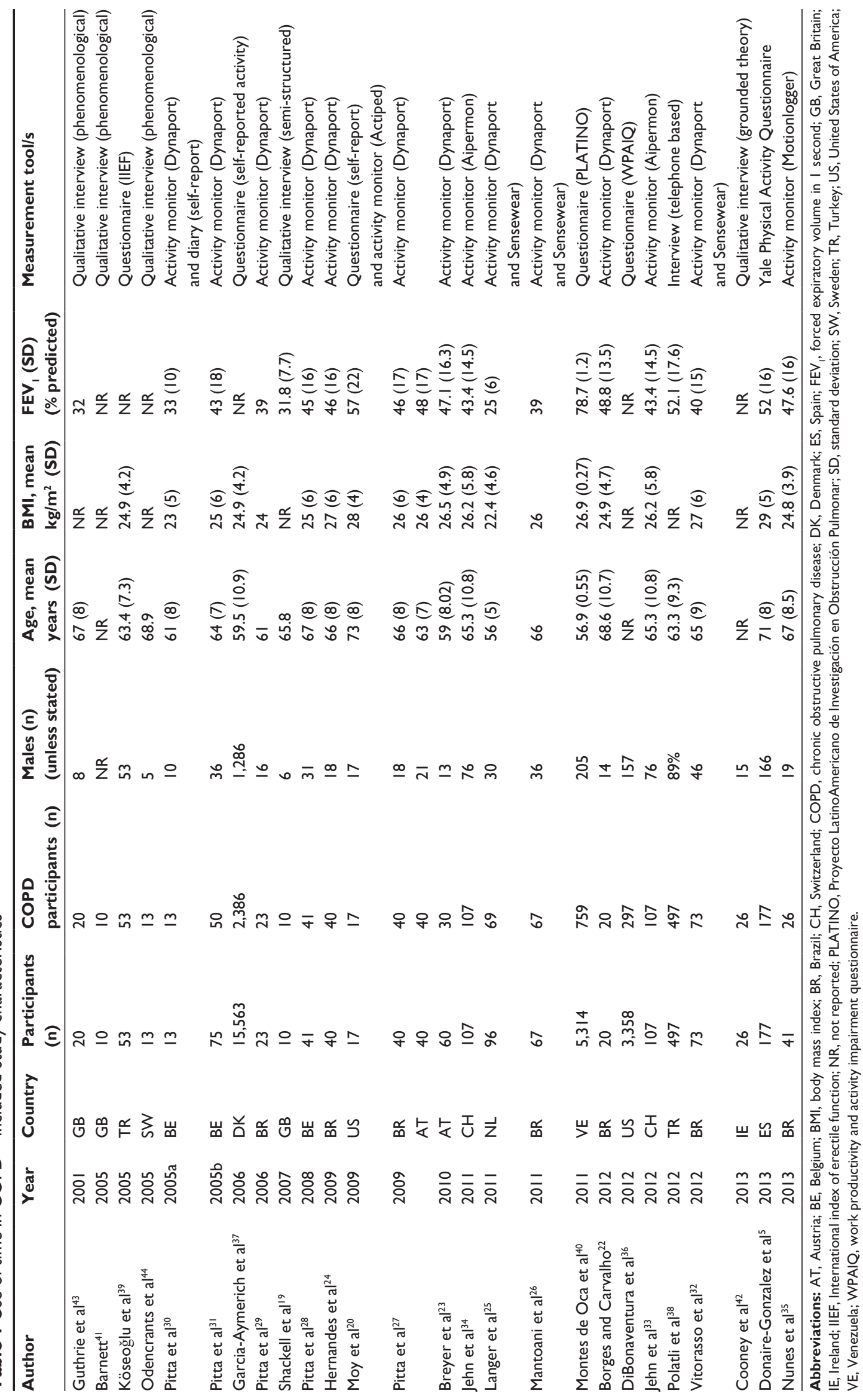


Table 2 Duration and frequency outcome data, synthesized into domains of activity

\begin{tabular}{|c|c|c|c|}
\hline Activity super domain & Activity & $\begin{array}{l}\text { Duration median (range), } \\
\text { minutes/day unless stated }\end{array}$ & $\begin{array}{l}\text { Frequency median (range), } \\
\text { episodes/week unless stated }\end{array}$ \\
\hline \multirow[t]{8}{*}{ Chores } & Shopping/walking in store $\mathrm{e}^{20,43}$ & & $2.25(0.5-4)^{\mathrm{a}}$ \\
\hline & Unloading groceries ${ }^{20}$ & & $3^{a}$ \\
\hline & Errands (post office) $)^{20}$ & & $3^{\mathrm{a}}$ \\
\hline & Preparing meals $\mathrm{s}^{20}$ & & $4.7^{\mathrm{a}}$ \\
\hline & Gardening 5,20 & $26(9-35)^{b}$ & 2. $1^{\mathrm{a}}$ \\
\hline & Collecting mail from mailbox $x^{20}$ & & $3.2^{\mathrm{a}}$ \\
\hline & Housework/chores/cleaning $20,38,42$ & $23(10-36)$ & $3.4^{\mathrm{a}}$ \\
\hline & Caretaking ${ }^{5}$ & $4(0-8)^{b}$ & \\
\hline \multirow[t]{4}{*}{ Quiet time } & Standing ${ }^{22,23,25-32}$ & $194(146-246)^{b}$ & \\
\hline & Sitting ${ }^{22,23,25-32}$ & $359(269-390)^{\mathrm{b}}$ & $I^{c}$ \\
\hline & Lying $22,23,25,27-31,38$ & $88(39-558)^{b}$ & \\
\hline & Reading (newspaper/book) ${ }^{38}$ & 60 & \\
\hline Screen time & Watching TV ${ }^{38}$ & 300 & \\
\hline \multirow[t]{3}{*}{ Self-care } & Showering/bathing ${ }^{41,43}$ & $60^{d}$ & $2.5(I-4)$ \\
\hline & Eating - dinner (sitting) $)^{44}$ & 60 & \\
\hline & Night-time waking/bathroom ${ }^{19}$ & & $2(I-3)^{e}$ \\
\hline \multirow[t]{4}{*}{ Sleep } & Sleep - night-time ${ }^{35,38}$ & $29 I(28 I-300)$ & \\
\hline & Sleep - daytime ${ }^{35}$ & 54 & \\
\hline & Lying awake (sleep latency) $)^{35,38}$ & $41(39-42)$ & \\
\hline & Lying awake (at night) ${ }^{35}$ & 96 & \\
\hline \multirow[t]{8}{*}{ Sociocultural } & Medical and/or chemist appointments ${ }^{20,36,43}$ & & $\mathrm{I}(0.3-I)^{\mathrm{a}}$ \\
\hline & Visiting the chemist ${ }^{43}$ & & I \\
\hline & Emergency room visits ${ }^{38}$ & & $0.6^{\mathrm{a}, \mathrm{f}}$ \\
\hline & Visiting friends $\mathrm{s}^{20,43}$ & & $2.5(I-4.1)^{\mathrm{a}}$ \\
\hline & Time spent outdoors ${ }^{38}$ & $168(\mid 32-204)$ & \\
\hline & Religious visits $^{43}$ & & $0.3^{b}$ \\
\hline & Sexual intercourse $\mathrm{e}^{39}$ & & 1.5 \\
\hline & Recreational/leisure time ${ }^{5}$ & $96(77-|4|)^{b}$ & \\
\hline \multirow[t]{2}{*}{ Sports/exercise } & Exercise $^{5,20}$ & $13(6-30)^{b}$ & $1.2(0.9-1.5)^{\mathrm{a}}$ \\
\hline & Dancing ${ }^{42}$ & & $2^{\mathrm{e}}$ \\
\hline \multirow[t]{4}{*}{ Transport } & Walking $20,22-34$ & $5 \mathrm{I}(2-66)^{\mathrm{b}}$ & $1.7(0.1-5.3)^{\mathrm{a}}$ \\
\hline & Cycling ${ }^{29-31,37}$ & $2(0-4)$ & $\mathrm{g}$ \\
\hline & Climbing stairs ${ }^{20}$ & & $4.8^{\mathrm{a}}$ \\
\hline & Travel in car, bus or train ${ }^{20}$ & & $5.7^{\mathrm{a}}$ \\
\hline \multirow[t]{3}{*}{ Work/study } & Employment $^{5,38,40}$ & $49(21-540)^{b}$ & \\
\hline & Absenteeism ${ }^{36}$ & $13^{\mathrm{b}, \mathrm{h}}$ & \\
\hline & Presenteeism ${ }^{36}$ & $58^{\mathrm{b}, \mathrm{h}}$ & \\
\hline
\end{tabular}

Notes: ${ }^{a}$ Selected outcomes converted from original frequency; bselected outcomes converted from original duration; 'frequency reported as hours after eating; dduration stated as 45-90 minutes/episode; ' $r$ reported frequency episodes/night; ' $r$ reported frequency episodes/year; ${ }^{8}$ study reports percentage of respondents cycling for a given duration ( $<0.5$ hours, $0.5-1$ hours, I-2 hours, and $>2$ hours) in winter and summer months; hassuming a 5-day working week.

Frequency-based outcomes were identified from questionnaire-based and/or qualitative studies; a selection of the most frequently reported outcomes are presented in Figure 2. In contrast, duration-based-activity outcomes were obtained almost exclusively from quantitative activity monitor assessments. As can be seen in Figure 3, where multiple assessments were identified, remarkable similarities were observed.

After assembling similar activities into their respective activity domains, we observed the following:

\section{Chores}

Chore-based data were identified from four studies. ${ }^{5,20,38,42}$ Most chore-based activities were identified from Moy et al' $\mathrm{s}^{20}$ study describing self-reported frequencies for selected activities undertaken by a group of US males. People with COPD engaged in fragmented short bouts of chore-based activities (housework/cleaning - $23 \mathrm{~min} / \mathrm{d}$; caring for others $-4 \mathrm{~min} / \mathrm{d}$; and gardening $-26 \mathrm{~min} / \mathrm{d})^{5,38,42}$ and many activities were undertaken with regularity (eg, more than once a week). ${ }^{20}$

\section{Quiet time}

Including activities such as listening to music, sitting quietly, and reading, we identified three quiet-time activities: standing (median $194 \mathrm{~min} / \mathrm{d}$ [range 146-246 $\mathrm{min} / \mathrm{d}$ ]), sitting (median $359 \mathrm{~min} / \mathrm{d}$ [range 269-390 $\mathrm{min} / \mathrm{d}$ ]), and lying (median $88 \mathrm{~min} / \mathrm{d}$ [range $39-558 \mathrm{~min} / \mathrm{d}]$ ). 


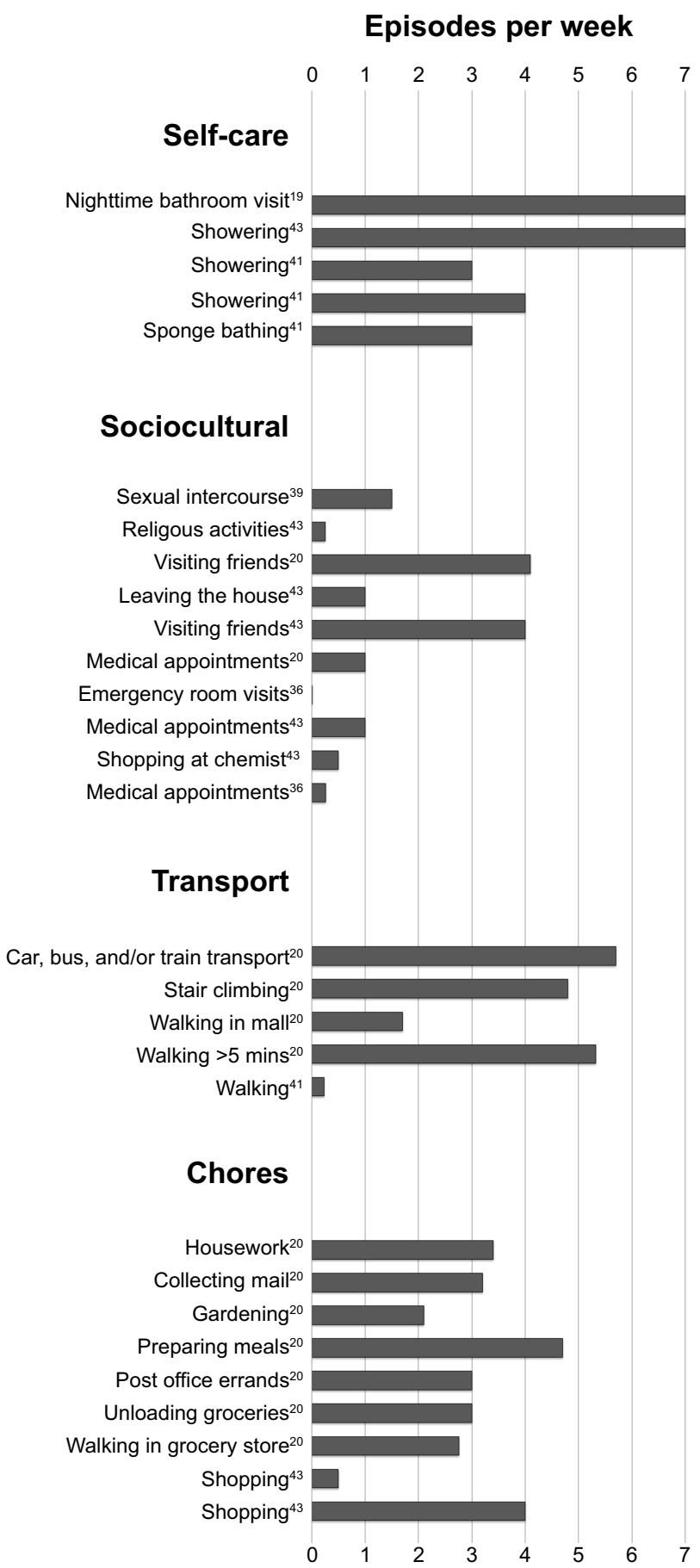

Figure 2 Frequency-based outcomes for activities reported in people with chronic obstructive pulmonary disease.

\section{Screen time}

Screen time included TV viewing as well as computer and/or console games. This review identified only one article reporting daily TV viewing time $(300 \mathrm{~min} / \mathrm{d}){ }^{38}$

\section{Self-care activities}

Self-care activities are those related to daily living (eg, showering, dressing, and eating). Reports in this

\section{Minutes per day}

$0 \quad 60120180240300360420480540600$

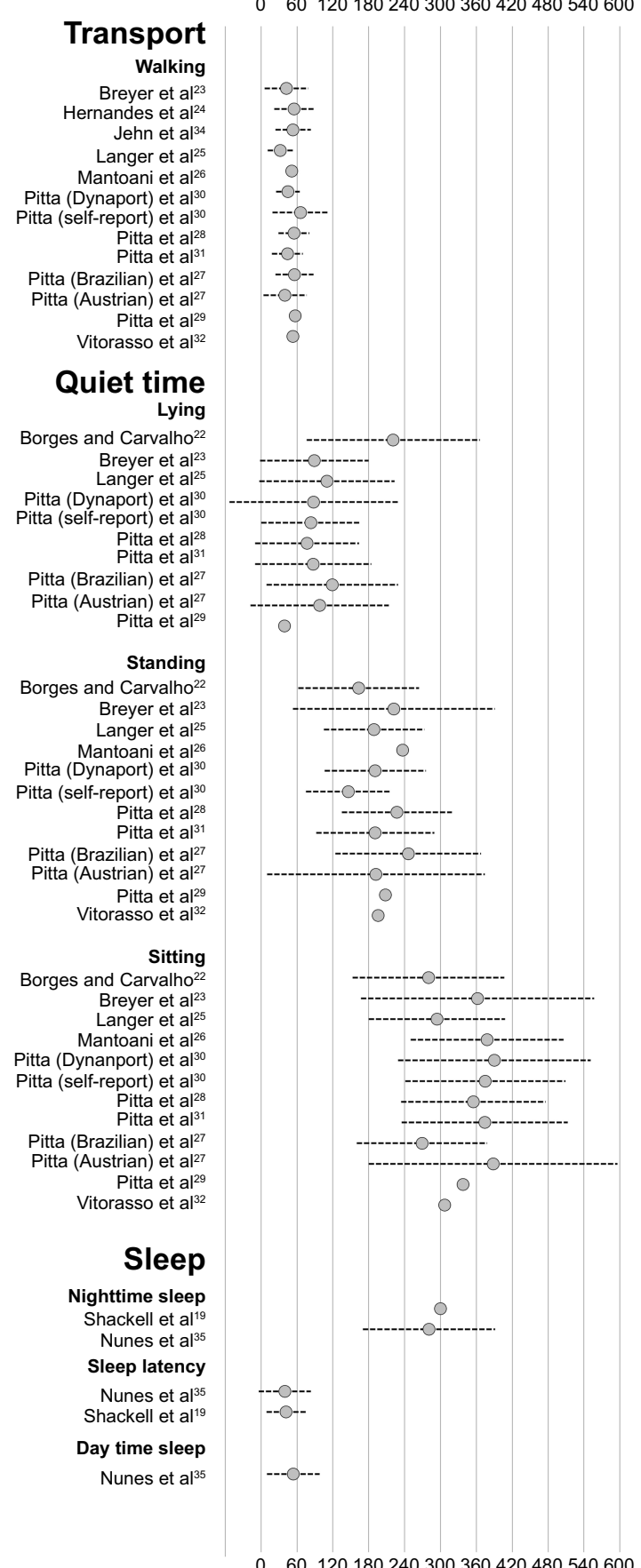

Figure 3 Duration-based outcomes for activities reported in people with chronic obstructive pulmonary disease.

category were limited to qualitative research ${ }^{41,43}$ consisting solely of showering and/or bathing. Bathing was undertaken with a median frequency of $2.5 \mathrm{ep} / \mathrm{w}$ lasting 60 minutes per episode.

\section{Sleep}

Two studies were identified reporting outcomes associated with sleep durations and/or patterns. ${ }^{35,38}$ Mean nocturnal sleep 
duration was $291 \mathrm{~min} / \mathrm{d}$ and episodes of daytime napping were also identified ( $54 \mathrm{~min} / \mathrm{d})$.

\section{Sociocultural}

This domain includes socializing and interacting with friends, family, and health care providers (eg, telephone conversations, medical appointments, intimate relations), and engaging in artistic activities (eg, music or drawing). Identified sociocultural activities included medical appointments (eg, medical and/or chemist), ${ }^{20,36,43}$ activities requiring strong social interactions (eg, visiting friends/family $[2.5 \mathrm{ep} / \mathrm{w}]^{20,43}$ ), spending time outside of the house $(168 \mathrm{~min} / \mathrm{d}),{ }^{38}$ engaging in religious activities (once per month), ${ }^{43}$ and general leisure/ recreational time $(96 \mathrm{~min} / \mathrm{d}) .^{5}$

\section{Sports/exercise}

The sports/exercise domain included activities relating to physical activity and exercise (eg, sports, home- and/or gym-based exercise). We identified only two such activities: exercise and dancing. These activities were undertaken infrequently $(1.2 \mathrm{ep} / \mathrm{w})^{20}$ and for limited durations (exercise - $13 \mathrm{~min} / \mathrm{d} ;^{5}$ dancing - maximum two dances in an evening ${ }^{42}$ ).

\section{Transport}

This domain included active and passive transport. Activetransport (eg, climbing stairs, walking, and cycling) activities require physical effort and are undertaken in order to get from one point to another. Passive-transport (eg, driving or being driven) activities include modalities of transport not requiring substantial physical effort.

Active-transport activities were limited to walking, cycling, and stair climbing. People with COPD consistently spent less than $60 \mathrm{~min} / \mathrm{d}$ walking (Figure 3). Walking frequency reports ranged from once a month to more than five times per week (Figure 2). From the four reports of cycling, we observed $38 \%$ of people with COPD reportedly cycling each year (less than $23 \%$ in winter $)^{37}$ but only short periods were reported (median $2 \mathrm{~min} / \mathrm{d}$ [range 0-4 min/d]). ${ }^{29-31}$ Stairclimbing reports were limited to one study $(4.8 \mathrm{ep} / \mathrm{w}),{ }^{20}$ as were reports of passive transportation (travelling in cars, buses, or trains $-5.7 \mathrm{ep} / \mathrm{w}) .^{20}$

\section{Work/study}

Time spent in paid employment was identified in three studies, ${ }^{5,38,40}$ while a fourth ${ }^{36}$ explored the impact COPD had on work productivity. A large difference in the time spent in paid employment was seen between Donaire-Gonzalez et al, ${ }^{5}$ Polatli et $\mathrm{al}^{38}$ and Montes de Oca et $\mathrm{al}^{40}$ (range $\left.21-540 \mathrm{~min} / \mathrm{d}\right)$.
The impact COPD had on employment in older US workers was explored by DiBonaventura et $\mathrm{al}^{36}$ who reported significant absenteeism (time away from work) and presenteeism (impaired work productivity) among people with COPD (13 $\mathrm{min} / \mathrm{d}$ and $58 \mathrm{~min} / \mathrm{d}$, respectively).

\section{Discussion}

This review was unable to identify a single study reporting comprehensive use of time profiles in people with COPD. It did identify 26 publications that together reported 37 discrete activities with associated durations and/or frequencies in which community-dwelling people with COPD reportedly engaged.

Significant heterogeneity was observed in population demographics, collection methodologies, and outcome measures across the 26 included studies. Activity outcomes ranged from broad posturally based outcomes (eg, sitting and standing) to discrete activities (eg, reading newspaper and/or books, gardening). More often than not, contextual information (eg, where activities were performed, and with whom) was lacking.

\section{Chores}

Reports of chore-based activities were limited and obtained almost exclusively from the study by Moy et al. ${ }^{20}$ Because of this, the range of chores presented is unlikely to reflect the entire spectrum of chores seen in larger COPD populations or COPD populations of different countries, cultures, or sexes.

\section{Quiet time}

Quiet-time activities were observed to be one of the most frequently reported outcomes. With the exception of lying, where three outliers were observed, surprising consistency was observed between quiet-time activities. Lying-time outliers included Pitta et al ${ }^{29}$ (who included both "active" [29 $\mathrm{min} / \mathrm{d}]$ and "inactive" [67 min/d] COPD groups), Borges and Carvalho ${ }^{22}$ (who report lying time [221 $\left.\mathrm{min} / \mathrm{d}\right]$ in a postexacerbation population), and Polatli et $\mathrm{al}^{38}$ (who report lying time [558 $\mathrm{min} / \mathrm{d}]$, likely including sleep). Contextual data of the seated, standing, or lying activities was limited to Polatli et al's ${ }^{38}$ report of newspaper reading.

\section{Screen time}

While many screen-based activities (eg, console gaming) might be unexpected leisure-time activities in this population, television is likely; and, with increasing computer usage in older-age populations, ${ }^{45}$ we considered it surprising that only one article reporting screen-based activities was identified. 


\section{Self care}

Understandably, most reports in this category were associated with reports of lived experiences and the difficulties people with COPD experienced in undertaking activities of daily living. Functional disabilities reportedly led to reductions in bathing frequencies (eg, "I used to bath daily, which I really do miss..."41) and longer showering durations (eg, "I just do things in stages..." ${ }^{\prime 41}$ ).

\section{Sleep}

Age, poor health, and activity limitations alter sleep patterns. ${ }^{46,47}$ People with COPD are likely to have all three of these factors so it is perhaps unsurprising that we identified considerably lower median sleep durations $(290 \mathrm{~min} / \mathrm{d}),{ }^{47}$ and episodes of night-time awakenings and daytime napping, ${ }^{35}$ than comparable age-matched adults.

\section{Sociocultural}

Eight distinct activities were identified within this category. Together, they highlight the higher health care needs experienced by this population (ie, medical appointments) as well as how important a supportive social environment is (ie, visiting friends).

\section{Sports/exercise}

Despite the importance most national guidelines place on optimizing physical activity, ${ }^{48,49}$ only three studies identified sports and/or exercise-based activities. Whether this is because national guidelines fail to reach end users, because people with COPD do not or cannot engage in sports, or whether, as a result of lacking contextual data, misclassification of activities occurred (eg, exercise-based walking episodes listed as transport) remains unclear.

\section{Transport}

Walking was one of the most commonly reported activities in this review with 12 separate reports identified, two of which presented identical outcome data. ${ }^{33,34}$ Unfortunately, studies exploring how walking time was accumulated (ie, bouts and durations) were limited to the study by Donaire-Gonzalez et $\mathrm{al}^{5}$ who reported bout lengths and frequencies only in the broad category of MVPA. Reports of walking frequency varied, most likely because of the context within which the data were collected. Frequency recalls are dependent on the way in which the question is posed. Direct questions such as those posed by Moy et $\mathrm{al}^{20}$ (eg, "How often did you...?") will elicit different responses to the more open ended questions that Barnett' ${ }^{41}$ qualitative interviews use (eg, "Tell me what it's like to...?”).
Failure to report contextual information makes it difficult to know why many activities in this category were undertaken (ie, stair climbing because of environmental factors [eg, two-story housing] or conscious choices [eg, for fitness], and travelling in cars, buses, or trains because it was unavoidable [eg, geographic isolation] or a conscious choice [ie, driving for pleasure]).

\section{Work/study}

The amount of time spent in paid employment varied significantly between studies. ${ }^{5,38,40}$ Plausible reasons for these differences include functional impairment levels $\left(\mathrm{FEV}_{1}\right)$ or population based factors (eg, type of work, national employment policies, accepted retirement age, or unemployment levels). One potential reason for the observed differences may be that data from both Donaire-Gonzalez et $\mathrm{al}^{5}$ and Polatli et a $\mathrm{l}^{38}$ were obtained from studies recruiting people diagnosed with COPD (eg, outpatients attendees), while Montes de Oca et al ${ }^{40}$ obtained employment data from home-based interviews included as part of a population-based survey. From DiBonaventura et al's ${ }^{36}$ work, we can see the impact COPD has on employment. Their inclusion of only older US workers and a failure to capture functional impairment (eg, $\mathrm{FEV}_{1}$ ), employment type (eg, blue collar versus white collar), and employment status (eg, $\mathrm{min} / \mathrm{d}$ or ep/w) limits the broader applicability of their data.

\section{Differences and/or similarities with existing COPD and population-level data}

While no published studies exploring use of time in people with COPD were identified, we were able to compare the findings of this review with unpublished data obtained from a study that assessed the MARCA's reliability and validity in people with COPD. ${ }^{17}$ Presenting 4-day averages of time-use data for 24 people with COPD (age $74.4 \pm 7.9$ years, $\mathrm{FEV}_{1}$ $54 \% \pm 13 \%$ ), similarities in the activity domains of screen time (300 $\mathrm{min} / \mathrm{d}$ versus $334 \mathrm{~min} / \mathrm{d})$, self-care $(120 \mathrm{~min} / \mathrm{d}$ versus $129 \mathrm{~min} / \mathrm{d}$ ), and transport (53 $\mathrm{min} / \mathrm{d}$ versus $50 \mathrm{~min} / \mathrm{d}$ ) were observed. The differences in the remaining activity domains were most likely due to variations in methodologies and emphases of the papers identified in this review.

Two population-based time-use surveys were identified the American Time Use Survey (ATUS) ${ }^{50}$ and the Harmonized European Time Use Survey (HETUS) ${ }^{51}$ - which present use-of-time data from similarly aged people in similar geographic locations to this review. Using telephone ${ }^{50}$ or paper diary ${ }^{51}$ recall collection methods, both surveys recorded 24-hour time-use profiles. As with this review, similar activities were combined into predefined activity groups 
(eg, ATUS: personal care, household activities, and civic/ religious; HETUS: self-care, sleep, household and family care, and volunteering). We identified similar activity types and/or domains within these surveys and converted comparable outcomes to $\mathrm{min} / \mathrm{d}$. Medians and averages (min/d) as well as the percentage of daily time devoted to each activity were calculated for each dataset, and differences with our data were explored (see Tables S6.1 and S6.2).

When compared this way, it appears people with COPD spend less time engaged in personal-care activities (self-care and sleeping) and chore-based activities (personal care-29\%; chores $-3 \%$ of their day) than similarly aged Americans (personal care $-48 \%$; chores $-14 \%$ of their day) and Europeans (personal care $-50 \%$; chores $-17 \%$ of their day) (Table S6.2). These findings should, however, be interpreted with caution as not all activity categories overlapped and we were only able to compare mutually exclusive activities and/or domains. Data skewing was also likely in our synthesis, especially for activities where very few data were reported (eg, chores).

\section{Activity domains synthesis - where does time go for people with COPD}

While recognizing our data's fragmentary nature, we constructed a theoretic composite activity profile. Presenting slightly more than 24 hours of individual activity data, most likely due to activity overlap between reported categories (eg, time spent sitting and television time), this composite describes people with COPD as having: limited nocturnal sleep (291 $\mathrm{min} / \mathrm{d})$; significant waking hours devoted to sedentary activities (sitting - $359 \mathrm{~min} / \mathrm{d}$; watching television $300 \mathrm{~min} / \mathrm{d}$; standing -194 $\mathrm{min} / \mathrm{d}$; lying - $88 \mathrm{~min} / \mathrm{d}$ ); very little engagement in physically demanding activities (walking $51 \mathrm{~min} / \mathrm{d}, 1.7 \mathrm{ep} / \mathrm{w}$; cycling $-2 \mathrm{~min} / \mathrm{d}$; exercise $-1.2 \mathrm{ep} / \mathrm{w}$ or $13 \mathrm{~min} / \mathrm{d}$ ); difficulty undertaking activities of daily living (eg, showering - $2.5 \mathrm{ep} / \mathrm{w}, 60 \mathrm{~min} / \mathrm{ep}$; preparing meals - $4.7 \mathrm{ep} / \mathrm{w}$ ); short frequent bouts of chores (eg, household cleaning $3.4 \mathrm{ep} / \mathrm{w}$ or $23 \mathrm{~min} / \mathrm{d}$; gardening $2.1 \mathrm{ep} / \mathrm{w}$ or $26 \mathrm{~min} / \mathrm{d}$ ); high health care needs (medical appointments - $1 \mathrm{ep} / \mathrm{w}$ ); and a strong reliance on social supports (eg, visiting friends $2.5 \mathrm{ep} / \mathrm{w}$ ). Excluding postural outcomes (eg, sitting, standing, and lying), few other activities afford enough data to draw confident conclusions; yet, even these postural outcomes lack sufficient detail to distinguish between the many discrete activities possible within a given posture.

\section{Limitations}

Our decision to include only peer-reviewed manuscripts, excluding grey literature (eg, letters, diaries, and narrative points of view) may have narrowed our findings because use-of-time reports may be more explicitly stated in nonpeer reviewed sources of literature. Finding such data would have been challenging and unachievable using conventional databases.

Use-of-time studies categorize activity into various domains, ${ }^{50,51}$ and while the majority of use-of-time studies use similar domains with significant overlap, subtle differences between studies remain. We synthesized our findings using one such set of domains; ${ }^{17}$ synthesizing activities into categories reported by others may have led to slightly different outcomes.

Finally, while functional-impairment assessments are often used to define COPD severity, frequent and significant variations in activity-based outcomes are found between individuals with similar degrees of functional impairment. Use-of-time and/or activity studies rarely report severity and/or functional-impairment as covariates, further limiting our findings.

\section{Use-of-time research - implications and future directions}

Use of time is a broader approach than physical-activity research, allowing exploration of how activity choices impact on health and wellbeing. As highlighted by this review, a coherent approach to recording use-of-time data in chronic disease populations is lacking, leading to incomplete and fragmented outcomes. A range of approaches and instruments are available for reporting, describing, and quantifying use of time, which range from time and motion studies to simple activity-specific recall questionnaires. The 2012 review by Foley et al $^{52}$ describes the psychometric properties of six use-of-time instruments commonly used in youth, which may provide researchers a useful point of reference when contemplating use-of-time research. The MARCA, from which the domains were used for data synthesis in this review, was one of the identified use-of-time tools.

A lack of published reference use-of-time data has meant assessing the efficacy of interventions based on international guidelines ${ }^{48,49}$ (eg, interventions aimed at optimizing physical function, improving self-management skills, and/or increasing physical activity), potentially lack the specificity required to identify improvements in individual activities relevant to people with COPD (eg, being able to mow the lawn without a break). By incorporating use-of-time outcome measures as efficacy measures, unique insights into when and how effective interventions can be introduced is likely. 
Finally, attempts to draw comparisons between our data and that of other studies shows that many distinct tools can be used to collect use-of-time data, and synthesizing activities into appropriate domains of activity can be subjective. Further research is required to provide a clear description of the available use-of-time tools and to provide standardized activity-domain hierarchies for use in future research.

\section{Conclusion}

This review demonstrates the paucity of data available to understand how people with COPD use their time. The corpus of information is small and fragmented, relies heavily on postural activity, and is skewed according to country, assessment methods, and disease severity, making synthesis challenging.

By synthesizing these fragmentary reports, we present a theoretical composite activity profile, albeit lacunary, detailing time use in people with COPD. Use of time is an important area of research, as increasing evidence links many of the comorbid conditions associated with COPD to the patterns of activity we have identified within this review, including engagement in low-energy-expending activities (eg, quiet time and screen time).

We propose that future research aiming to describe patterns of activity in people with COPD should include: detailed activity profiles of at least 1 full day (ie, 24 hours of use-of-time data using validated time-use diaries or useof-time tools), where possible capture contextual factors (eg, where activities were undertaken, with whom, and their associated enjoyment level), and longitudinal cohorts facilitating tracking activity pattern changes resultant from either disease progression or distinct treatment approaches. In addition, we propose both objective activity monitoring and self-report data be included in future studies, allowing links to be drawn between self-report and objective data. By approaching research in this way, a clearer understanding of how people with COPD spend their time and whether or not our current treatments are effective in promoting and sustaining healthy lifestyle choices should emerge.

\section{Disclosure}

The authors report no conflicts of interest in this work.

\section{References}

1. Forgas JP, Williams KD, Laham SM. Social motivation: conscious and unconscious processes. New York: Cambridge University Press; 2005.

2. Pitta F, Troosters T, Probst VS, Spruit MA, Decramer M, Gosselink R. Quantifying physical activity in daily life with questionnaires and motion sensors in COPD. Eur Respir J. 2006;27(5):1040-1055.
3. Sandland CJ, Singh SJ, Curcio A, Jones PM, Morgan MD. A profile of daily activity in chronic obstructive pulmonary disease. $J$ Cardiopulm Rehabil. 2005;25(3):181-183.

4. Watz H, Waschki B, Meyer T, Magnussen H. Physical activity in patients with COPD. Eur Respir J. 2009;33(2):262-272.

5. Donaire-Gonzalez D, Gimeno-Santos E, Balcells E, et al. Physical activity in COPD patients: patterns and bouts. Eur Respir J. 2013; 42(4):993-1002.

6. Troosters T, Sciurba F, Battaglia S, et al. Physical inactivity in patients with COPD, a controlled multi-center pilot-study. Resp Med. 2010;104(7):1005-1011.

7. Waschki B, Spruit MA, Watz H, et al. Physical activity monitoring in COPD: compliance and associations with clinical characteristics in a multicenter study. Respir Med. 2012;106(4):522-530.

8. Bak TH, Nissan JJ, Allerhand MM, Deary IJ. Does bilingualism influence cognitive aging? Ann Neurol. 2014;75(6):959-963.

9. Hanna-Pladdy B, MacKay A. The relation between instrumental musical activity and cognitive aging. Neuropsychology. 2011;25(3):378-386.

10. Steger MF, Kashdan TB. Depression and Everyday Social Activity, Belonging, and Well-Being. J Couns Psychol. 2009;56(2):289-300.

11. Joseph NT, Kamarck TW, Muldoon MF, Manuck SB. Daily marital interaction quality and carotid artery intima-medial thickness in healthy middle-aged adults. Psychosom Med. 2014;76(5):347-354.

12. Moher D, Liberati A, Tetzlaff J, Altman DG, The PG. Preferred Reporting Items for Systematic Reviews and Meta-Analyses: The PRISMA Statement. PLoS Med. 2009;6(7):e1000097.

13. Letts L, Wilkins S, Law M, Stewart D, Bosch J, Westmorland M. Guidelines for Critical Review Form: Qualitative Studies (Version 2.0). McMaster University Occupational Therapy Evidence-Based Practice Research Group; 2007. Available from: http://www.srs-mcmaster.ca/ Portals/20/pdf/ebp/qualguidelines_version2.0.pdf. Accessed November 21, 2014.

14. Letts L, Wilkins S, Law M, Stewart D, Bosch J, Westmorland M Critical Review Form - Qualitative Studies (Version 2.0). McMaster University; 2007 [cited August 16, 2014]. Available from: http:// www.srs-mcmaster.ca/Portals/20/pdf/ebp/qualreview_version2.0.pdf. Accessed August 16, 2014.

15. Law M, Stewart D, Pollock N, Letts L, Bosch J, Westmorland M. Critical Review Form - Quantitative Studies. McMaster University; 1998 [cited August 16, 2014]. Available from: http://www.srs-mcmaster.ca/ Portals/20/pdf/ebp/quanreview.pdf. Accessed August 16, 2014.

16 Law M, Stewart D, Letts L, Pollock N, Bosch J, Westmorland M. Guidelines for Critical Review Form - Quantitative Studies. McMaster University Occupational Therapy Evidence-Based Practice Research Group. 1998. Available from: http://www.srs-mcmaster.ca/Portals/20/ pdf/ebp/quanguidelines.pdf. Accessed November 21, 2014.

17. Hunt T, Williams MT, Olds TS. Reliability and validity of the multimedia activity recall in children and adults (MARCA) in people with chronic obstructive pulmonary disease. PLoS One. 2013;8(11):e81274.

18. Ridley K, Ainsworth BE, Olds TS. Development of a compendium of energy expenditures for youth. Int J Behav Nutr Phys Act. 2008;5:45

19 Shackell BS, Jones RC, Harding G, Pearse S, Campbell J. 'Am I going to see the next morning?' A qualitative study of patients' perspectives of sleep in COPD. Prim Care Respir J. 2007;16(6):378-383.

20 Moy ML, Matthess K, Stolzmann K, Reilly J, Garshick E. Free-living physical activity in COPD: assessment with accelerometer and activity checklist. J Rehabil Res Dev. 2009;46(2):277-286.

21. Bossenbroek L, ten Hacken NH, van der Bij W, Verschuuren EA, Koëter GH, de Greef MH. Cross-sectional assessment of daily physical activity in chronic obstructive pulmonary disease lung transplant patients. J Heart Lung Trans. 2009;28(2):149-155.

22. Borges RC, Carvalho CR. Physical activity in daily life in Brazilian COPD patients during and after exacerbation. COPD. 2012;9(6): 596-602.

23. Breyer MK, Breyer-Kohansal R, Funk GC, et al. Nordic walking improves daily physical activities in COPD: a randomised controlled trial. Respir Res. 2010;11:112. 
24. Hernandes NA, Teixeira Dde C, Probst VS, Brunetto AF, Ramos EM, Pitta F. [Profile of the level of physical activity in the daily lives of patients with COPD in Brazil]. J Bras Pneumol. 2009;35(10):949-956. English, Portuguese.

25. Langer D, Cebrià i Iranzo MA, Burtin C, et al. Determinants of physical activity in daily life in candidates for lung transplantation. Respir Med. 2012;106(5):747-754.

26. Mantoani LC, Hernandes NA, Guimarães MM, Vitorasso RL, Probst VS, Pitta F. Does the BODE index reflect the level of physical activity in daily life in patients with COPD? Rev Bras Fisioter. 2011;15(2):131-137. English, Portuguese.

27. Pitta F, Breyer MK, Hernandes NA, et al. Comparison of daily physical activity between COPD patients from Central Europe and South America. Respir Med. 2009;103(3):421-426.

28. Pitta F, Troosters T, Probst VS, Langer D, Decramer M, Gosselink R. Are patients with COPD more active after pulmonary rehabilitation? Chest. 2008;134(2):273-280.

29. Pitta F, Troosters T, Probst VS, Lucas S, Decramer M, Gosselink R. Potential consequences for stable chronic obstructive pulmonary disease patients who do not get the recommended minimum daily amount of physical activity. J Bras Pneumol. 2006;32(4):301-308.

30. Pitta F, Troosters T, Spruit MA, Decramer M, Gosselink R. Activity monitoring for assessment of physical activities in daily life in patients with chronic obstructive pulmonary disease. Arch Phys Med Rehabil. 2005;86(10):1979-1985.

31. Pitta F, Troosters T, Spruit MA, Probst VS, Decramer M, Gosselink R. Characteristics of physical activities in daily life in chronic obstructive pulmonary disease. Am J Respir Crit Care Med. 2005;171(9):972-977.

32. Vitorasso R, Camillo CA, Cavalheri V, et al. Is walking in daily life a moderate intensity activity in patients with chronic obstructive pulmonary disease? Eur J Phys Rehabil Med. 2012;48(4):587-592.

33. Jehn M, Schindler C, Meyer A, Tamm M, Schmidt-Trucksäss A, Stolz D. Daily walking intensity as a predictor of quality of life in patients with chronic obstructive pulmonary disease. Med Sci Sports Exerc. 2012;44(7):1212-1218.

34. Jehn M, Schmidt-Trucksäss A, Meyer A, Schindler C, Tamm M, Stolz D. Association of daily physical activity volume and intensity with COPD severity. Respir Med. 2011;105(12):1846-1852.

35. Nunes DM, de Bruin VM, Louzada FM, et al. Actigraphic assessment of sleep in chronic obstructive pulmonary disease. Sleep Breath. 2013;17(1):125-132.

36. DiBonaventura Md, Paulose-Ram R, Su J, et al. The impact of COPD on quality of life, productivity loss, and resource use among the elderly United States workforce. COPD. 2012;9(1):46-57.

37. Garcia-Aymerich J, Lange P, Benet M, Schnohr P, Antó JM. Regular physical activity reduces hospital admission and mortality in chronic obstructive pulmonary disease: a population based cohort study. Thorax. 2006;61(9):772-778.

38. Polatli M, Bilgin C, Şaylan B, et al. A cross sectional observational study on the influence of chronic obstructive pulmonary disease on activities of daily living: The COPD-Life study. Tuberk Toraks. 2012;60(1):1-12.
39. Köseoğlu N, Köseoğlu H, Ceylan E, Cimrin HA, Ozalevli S, Esen A. Erectile dysfunction prevalence and sexual function status in patients with chronic obstructive pulmonary disease. J Urol. 2005;174(1):249-252.

40. Montes de Oca M, Halbert RJ, Talamo C, et al. Paid employment in subjects with and without chronic obstructive pulmonary disease in five Latin American cities: The PLATINO study. Int J Tuberc Lung Dis. 2011;15(9):1259-1264.

41. Barnett M. Chronic obstructive pulmonary disease: a phenomenological study of patients' experiences. J Clin Nurs. 2005;14(7):805-812.

42. Cooney A, Mee L, Casey D, et al. Life with chronic obstructive pulmonary disease: striving for 'controlled co-existence'. J Clin Nurs. 2013;22(7-8):986-995.

43. Guthrie SJ, Hill KM, Muers MF. Living with severe COPD. A qualitative exploration of the experience of patients in Leeds. Respir Med. 2001;95(3):196-204.

44. Odencrants S, Ehnfors M, Grobe SJ. Living with chronic obstructive pulmonary disease: part I. Struggling with meal-related situations: experiences among persons with COPD. Scan J Caring Sci. 2005;19(3):230-239.

45. Morris A, Goodman J, Brading H. Internet use and non-use: views of older users. Universal Access in the Information Society. 2007;6(1):43-57.

46. Newman AB, Enright PL, Manolio TA, Haponik EF, Wahl PW. Sleep disturbance, psychosocial correlates, and cardiovascular disease in 5,201 older adults: the Cardiovascular Health Study. J Am Geriatr Soc. 1997;45(1):1-7.

47. Ohayon MM, Carskadon MA, Guilleminault C, Vitiello MV. Metaanalysis of quantitative sleep parameters from childhood to old age in healthy individuals: developing normative sleep values across the human lifespan. Sleep. 2004;27:1255-1273.

48. McKenzie DK, Frith PA, Burdon JG, Town GI. The COPDX Plan: Australian and New Zealand guidelines for the management of chronic obstructive pulmonary disease 2003. Med J Aust. 2003;178(6 Suppl): S1-S40.

49. American Thoracic Society/European Respiratory Society Task Force. Standards for the Diagnosis and Management of Patients with COPD [webpage on the Internet]. Version 1.2. New York: American Thoracic Society; 2004 [updated 2005 September 8]. Available from: http://www. thoracic.org/go/copd. Accessed November 21, 2014.

50. American Time Use Survey - 2013 Results. U.S. Department of Labour, 201118 June 2014. Report No: Contract No: USDL-14-1137. Available from: http://wwww.bls.gov/tus/. Accessed November 21, 2014.

51. European Communities. Time use at different stages of life - Results from 13 European countries: July 2003. Luxembourg: Office for Official Publications of the European Communities; 2003. Available from: http://epp.eurostat.ec.europa.eu/cache/ITY_OFFPUB/KS-CC-03-001/ EN/KS-CC-03-001-EN.PDF. Accessed November 21, 2014.

52. Foley L, Maddison R, Olds T, Ridley K. Self-report use-of-time tools for the assessment of physical activity and sedentary behaviour in young people: systematic review. Obes Rev. 2012;13(8):711-722.
International Journal of COPD

\section{Publish your work in this journal}

The International Journal of COPD is an international, peer-reviewed journal of therapeutics and pharmacology focusing on concise rapid reporting of clinical studies and reviews in COPD. Special focus is given to the pathophysiological processes underlying the disease, intervention programs, patient focused education, and self management protocols.

\section{Dovepress}

This journal is indexed on PubMed Central, MedLine and CAS. The manuscript management system is completely online and includes a very quick and fair peer-review system, which is all easy to use. Visit $\mathrm{http}: / / \mathrm{www}$.dovepress.com/testimonials.php to read real quotes from published authors. 